\title{
MEASURES TAKEN BY THE HOTELIERS TO OVERCOME THE COVID-19 IMPACT
}

\author{
Noor Azimin Zainol ${ }^{1}$, Eshaby Mustafa ${ }^{2}$ \& Nurhazani Mohd Shariff ${ }^{3}$ \\ ${ }^{1,3}$ Langkawi International Research Centre for Tourism \& Hospitality, School of Tourism, Hospitality \& \\ Event Management, Universiti Utara Malaysia (UUM), \\ ${ }^{2}$ School of Tourism, Hospitality \& Event Management, Universiti Utara Malaysia (UUM), \\ (azimin@uum.edu.my, eshaby@uum.edu.my, hazani@uum.edu.my)
}

\begin{abstract}
The hotel industry which supports the tourism industry, plays a crucial part in Malaysia's economic development. Unfortunately, the outbreak of COVID-19 has caused the tourism industry to make huge losses, both locally and globally in terms of cancellation of all travel and tour activities, including accommodations. Many researchers have attempted to highlight the effects of COVID-19 pandemic on various sectors, however limited studies have been conducted to address how the hospitality industry can mitigate this situation to recover and revive the hospitality industry. Recent reported figures lack of empirical and academic underpinning. This paper aims to fill the gap. It is thus imperative to examine the measures being taken by hoteliers in order to overcome this unprecedented scenario. Therefore, this study's aim is to highlight the measures taken by the hoteliers to overcome the impact of the ongoing COVID-19 pandemic in terms of staff employment, working terms and hotels' loss of revenue. A qualitative research method was deemed appropriate to investigate this scenario. The data collection was founded based on the Grounded Theory approach and feedback was collected through semi-structured interviews among 15 staffs from the Food and Beverage, Accounts and Front Office departments which were selected using purposive sampling from five different hotels in Penang. The findings showed that all of the respondents have come to the agreement that the measures taken by their hotels to overcome the impact of the COVID-19 pandemic in terms of staff employment and work conditions were to lower the hotel operations costs. This was done by reducing the number of employees and reducing staffs' salaries. Other measures taken by the hotel management to mitigate the pandemic's impact include increasing room sales, venturing into other services, and extending bookings for events. The findings of this study have some practical implications for hoteliers as they can adopt similar strategies in their respective hotels as a means of coping with impact of the COVID-19 pandemic.
\end{abstract}

KEYWORDS: COVID-19, Hotel Industry, Impact, Measures to Overcome COVID-19, Grounded Theory

\section{PURPOSE AND BACKGROUND}

Many researchers have attempted to highlight the effects of COVID-19 pandemic on various sectors (Bonaccorsi et al., 2020; Ashraf, 2020; Baker et al., 2020), however limited empirical studies have been conducted to address how the tourism and hospitality industry mitigated this situation.

This was also supported by Yacoub and ElHajjar (2020), who conducted a study to address the managerial reactions of the hotel industry during the COVID-19 pandemic and the potential strategic approaches that hotels might adopt in the future. Although there were quite a number of recorded figures and measures done by hoteliers being addressed in printed medias especially newspapers recently, however these figures lack of empirical and academic underpinning. 
Thus, this paper aims to fill in the gap in the research that maps a way forward as a guide to recover and revive the hospitality industry. Especially since the tourism and hotel industry is one of the biggest contributors to the Malaysian economy. Thus, it is critical to understand the strategies taken by hoteliers as the information gathered would be useful for other hoteliers in the industry who are still struggling to overcome the challenges of COVID-19 towards their business operations.

Hence, a study to explore the measures taken by hotels in order to fight the impact of COVID-19 pandemic in terms of staff employment, working terms and hotels' loss of revenue is worth conducting. These findings could not only inform the authorities on the appropriate support that could be provided to assist in the post-COVID recovery of hotel industry in Malaysia, but also as a reference point by other hoteliers.

Therefore, the objective of this study was to identify the measures taken by the hotel industry to mitigate the impact of COVID-19 based on Grounded Theory approach.

\section{METHODOLOGY}

This study is exploratory in nature as not a lot of researches has been done regarding this issue, especially concerning the staff employment, working terms and hotels' loss of revenue. Thus, this study seeks to gain insights on the informants' responses regarding the measures taken by hoteliers to mitigate the impact of COVID-19 towards the hotel industry.

Therefore, a qualitative method was applied to seek the abundance of informants' responses regarding the purpose of the study. The data collection was founded based on the Grounded Theory approach, a methodology initially introduced by Glaser and Strauss (1969). Grounded theory purports that the collected data based on informants' feedback will be utilized to create theories, and according to Strauss and Corbin (1998), relevant aspects could be discovered under specific social fields when utilizing this theory.

Although Grounded Theory does not necessarily produce a formal theory every time it is applied, it has aided in constructing conceptual analyses of a particular experience. Data collection was done via semi-structured interviews among 15 staff members from the Food and Beverage, Accounts and Front Office departments who were selected using purposive sampling from five different hotels in Penang.

The collected data was then transcribed and analysed via thematic content analysis to make sense of the data and coming out with appropriate themes to answer the study's objective.

\section{FINDINGS}

The findings revealed that all informants agreed that the measures taken by their hotels to overcome the COVID-19 impacts in terms of staff employment and working terms was to lower down the hotel operation cost. This was done by reducing the number of employees and also reducing staffs' income.

In terms of reducing the number of employees, steps taken include halting the hiring of part-time staff and implementing staggered or flexible working schedule, while unpaid leaves and salary cuts were used as other ways to cut the hotel operation costs as measures to decrease the staffs' salaries. Apart from that, other measures taken by the hotel management to overcome the pandemic's impact in terms of reducing the hotel loss included increasing room sales, venturing into other services, and extending bookings for events. 


\section{CONCLUSION}

The Grounded Theory approach which acts as the underpinning theory for this study has provided the necessary conceptual underpinnings in terms of bringing forward some practical measures which could be replicated by other hoteliers in the case of any pandemic.

Overall, based on the informants' feedback during the interview sessions, they were aware and knowledgeable about COVID-19 and they were also able to highlight the steps taken by the hotel industry in mitigating the impact of COVID-19 towards the employment of staff and working terms, and also how to reduce the loss of hotel revenue.

The findings managed to adequately answer the research aims of the undertaken study and provide useful insights on measure undertaken by hoteliers to mitigate COVID-19 impact which supported the existing literature gap. It has become critical to conduct researches similar to the undertaken study in order to identify and highlight the strategies that will help the hotel industry to sustain their businesses despite the pandemic.

Thus, this will aid in conveying some innovative ideas as alternative strategies in redesigning Malaysia's tourism landscape in this challenging situation.

\section{CONTRIBUTION/PRACTICAL IMPLICATIONS}

The findings of this study is deemed practical especially on how the different hotels coped with impacts of COVID-19 from the aspect of staff employment and working terms, in addition to mitigating the loss of revenue that might be caused by the pandemic as they could be a good source of reference for industry players.

Further, the findings of this study have practical implication for hoteliers as they could adopt or improvise similar strategies in their respective hotels to overcome the challenges posed by the COVID-19 pandemic. In addition, the findings would help inform the authorities regarding the appropriate support that could be provided to assist the post-COVID recovery of the hotel industry.

This measure may provide some basis for theoretical contribution for this kind of study, especially concerning the unique nature of the hospitality industry. It has become critically important now for the hoteliers to look into ways to maintain the operation of its facilities at the most economically feasible scale despite the plummeting demand for accommodation. This is to ensure continuity of business, apart from generating considerable amount of revenue to sustain its facilities, employees and potential influx of guests. Thus, the management of hotels which are equally affected by COVID-19 may consider and adopting similar measures implemented by other hotels as part of their efforts to face the challenges posed by the pandemic.

For instance, strategies such as offering unpaid leave, pay cuts, reshuffling of staff work schedule and implementation of staggered working hours may provide a better solution for employee management during the pandemic instead of retrenchment, as this would help the hotels to retain its talents and manpower until the situation improves in the future. On the other hand, alternative services offered by the affected hotels such as food delivery or even renting their parking lots may also be adopted by other hoteliers in order to diversify their ways of generating income as room sales takes a nosedive (Solomon, 2020).

The findings of this study also have practical implication towards the authorities and ministries responsible for the operations and sustainability of hotel industry during the strike of COVID-19. The 
information gathered through this study may inform the relevant authorities and ministries of the challenges faced by the hoteliers which urgently need their interventions, both for short and long-term sustainability.

\section{REFERENCES}

Herédia-Colaço, V., \& Rodrigues, H. (2021). Hosting in turbulent times: Hoteliers' perceptions and strategies to recover from the Covid-19 pandemic. International Journal of Hospitality Management, 94, 1-12.

Rodríguez-Antón, J. M., \& Alonso-Almeida, M. d. M. (2020). COVID-19 impacts and recovery strategies: The case of the hospitality industry in Spain. Sustainability, MDPI, Open Access Journal, 12, 1-1.

Strauss, A., \& Corbin, J. (1998). Basics of qualitative research: Techniques and procedures for developing grounded theory (2nd ed.). California: Thousand Oaks. 